\title{
PARTICIPANTS WANTED FOR EMOTION PROBING
}

Drs Helen Chapman, Susan Chipchase and Roger Bretherton from the School of Psychology at the University of Lincoln have been awarded £77,357 from The Shirley Glasstone Hughes Trust Fund to investigate Dentists' emotions and clinical decision making: individual differences in susceptibility and the development of a coping package.

During this 15-month project, the researchers will explore the emotions experienced by dentists in their clinical work and identify the possible implications of these emotions.

An early information gathering stage will inform the development of a coping skills package, based on cognitive behavioural principles, which will be evaluated in the last stage of the research.

'The ultimate aim of this research is that this coping skills package will be included as part of dentists' continuing professional development to increase their awareness of how their emotions may impact on their clinical work and equip them with the skills to cope with these emotions in their dentistry work, said Dr Chapman.

The research question was originally posed on the Primary Dental Research Forum. A survey via the discussion forum of GDPUK found that $60 \%$ of participants felt that their clinical decision making was affected by fear on a daily basis. Contributors also felt that training to help cope with the issue is needed.

The research team is currently seeking to recruit a pool of volunteers from the Lincolnshire area who might be interested in participating in an hour-long face-toface interview to discuss this issue, which will be conducted at their practice. From this pool, the team hopes to draw a sample of dentists who represent a complete cross section of primary care dentists.

If you think you might be interested in participating, please contact Helen Chapman via hchapman@lincoln.ac.uk or 0796455 6316. You will then be sent a full description of the study so that you can make an informed choice about possible participation.

\section{SEARCH FOR OLDEST DENTAL CHAIR}

Fedesa, one of the world's leading manufacturers of dental chairs, is launching a search for the oldest dental chair in the UK and Ireland, to help celebrate the opening of their new division, Fedesa UK.

Fedesa UK would like dentists and owners of dental practices to find photos of the oldest chairs on their premises.

Fedesa have been supplying chairs from their Spanish headquarters for more than 40 years, but the dental chair was invented by Josiah Flagg in the USA in 1790.

The competition winners will receive a Tactys tempered glass keyboard worth over $£ 400$.

Entries should be sent by email toinfo@fedesadental. co.uk before 30 April 2012.

\section{SCIENCE MUSEUM WILL COLLECT 3D FACIAL IMAGES}

A new project called 'Me in 3D' enables visitors to the Science Museum in London to have their photograph taken using the latest 3D imaging technology. The pictures taken will form the largest database of 3D facial images in the world.

The project is a collaboration between UCL Eastman Dental Institute, Great Ormond Street Hospital (GOSH) and University College Hospital (UCH). The database will help with vital research into the complexities of face shape to improve treatment for patients with facial disfigurement.

The Eastman Dental Institute's department of craniofacial growth and development has a first class reputation for the correction of dental and facial problems. Orthodontic and surgical teams from the Institute, Eastman Dental Hospital, GOSH and UCH produce fantastic improvements in appearance and function, transforming the lives of those affected physically and psychologically.

'Me in 3D' is a part of the Science Museum's ongoing Live Science programme, to encourage visitors to get involved in contemporary science and cuttingedge research.

The event is now underway and will run until 10 April 2012. 